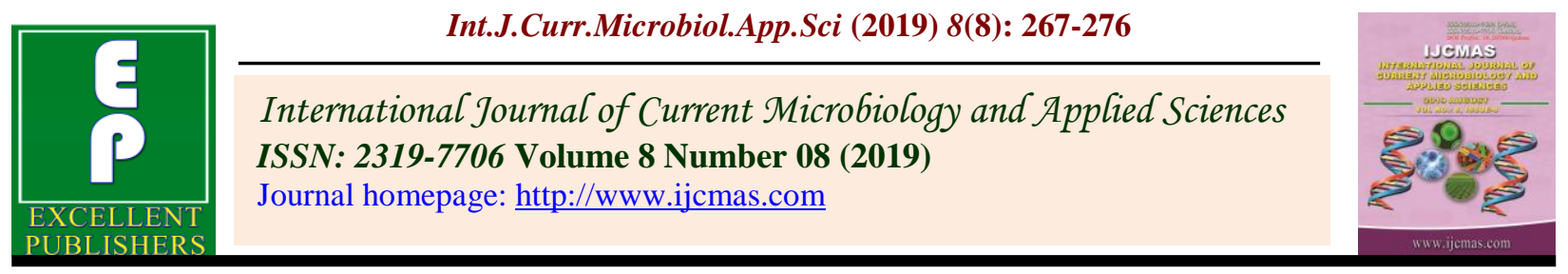

Original Research Article https://doi.org/10.20546/ijcmas.2019.808.032

\title{
Designing of Kurti Using Traditional Designs of Manipur through Transfer Printing
}

\author{
Laimayum Jogeeta Devi*, Anita Rani and Manisha Gahlot
}

Department of Clothing and Textiles, College of Home Science, GBPUAT, Pantnagar, India

*Corresponding author

\section{A B S T R A C T}

\begin{tabular}{|l|}
\hline Ke y w o r d s \\
$\begin{array}{l}\text { Architectural } \\
\text { designs, Textile } \\
\text { designs, Lifestyle } \\
\text { products, Transfer } \\
\text { printing }\end{array}$ \\
\hline Article Info \\
\hline $\begin{array}{l}\text { Accepted: } \\
\text { 04 July } 2019 \\
\text { Available Online: } \\
\text { 10 August } 2019\end{array}$ \\
\hline
\end{tabular}

The dynamism of fashion industry has forced retailers to desire low cost, versatility, flexibility and quality in design and speed to market. Highly competitive fashion market constantly needs to 'refresh' product ranges which led to the appearance of small collections of merchandise. The rich traditional heritage, across the length and width of our country, offers diverse inspiration to the textile designers today. In this context, the designs of Manipur both architectural as well as textile designs were explored as an option to develop a new range of lifestyle products which is unique and distinct in its category. The study was an attempt to develop lifestyle products through surface enrichment using transfer printing. Textiles and architectural designs of Manipur were collected form secondary sources and adapted through CorelDraw for suitability to printing without compromising their traditional values. This involves various steps like formation of line design patterns, design combinations, design arrangements and colour ways. Out of the five aesthetic parameters, printing quality scored the highest weighted mean score followed by the parameter uniqueness of motifs and design arrangement and aesthetic parameter suitability of colour combination used in design arrangement scored the least weighted mean score. Overall, the printed kurti was accepted by the consumers.

\section{Introduction}

Fashion is the style or styles most popular at a given time i.e., it implies three components viz., style, change and acceptance. The dynamism of the fashion has prompted the young population throughout the world to adopt distinct yet the classic products to showcase their lifestyles. Consumers prefer more of the utility products that reflect their lifestyle effectively. Today's highly competitive fashion market hence constantly needs to 'refresh' product ranges. This has led to the appearance of small collections of merchandise developed on the idea of 'Here Today, Gone Tomorrow' to suit the demands of the consumers. The dynamic character of the fashion industry has forced retailers to come up with low cost, flexibility and quality in design and speed to market.

The market of lifestyle products can be considered from two different aspects, lifestyle that defines products and products that define lifestyle. Most often the lifestyle products are the luxury products. It becomes 
inevitable part of life for high income group of people who are living luxurious life. Lifestyle products ranging from personal accessories to household articles are the medium of expression of their status and luxurious, cosy and modern lifestyle. The researchers are trying to identify the delineation of lifestyles called psychographics. Psychographics deals with psychological, sociological and anthropological factors of the consumers that separate them on the basis of differences in their lifestyles. The artisans and craftsmen have preserved the local crafts through the material culture viz., array of woven, resist dyed, painted and printed textiles till today with some slight modification from the pure traditional one due to changing consumers' demand, market conditions and various other social reasons. Though, modified for various reasons, the craft items are still rooted in traditional values. For example, a successful and a renowned Indian designer Ritu Kumar developed a unique style by the utilization of ancient designs and traditional crafts innovatively to produce a classic style. Likewise Anita Dongree has come up with a brand "Grassroots" tapping traditional crafts to create lifestyle apparel line involving local artisans.

Traditional crafts form a major cottage industry sector in the country. The local enterprises dealing with traditional crafts helps in checking population migration, broadening of design base and communication of culture among the global consumers through their use in contemporary lifestyles. Some researchers had explored traditional crafts for development of designs that are suitable for application on textile surface of household items (curtains, cushions, bags, bed sheets, pillow cover, etc.) and such enriched textiles were used in apparel (kurti, skirt and stole). Jangwan, 2009; Karolia and Buch, 2008; Karoliaand Prakash, 2014; Kaur et al., 2014; Joshi, 2004; Deviand Srivastava 2013; Pandya and Thoudam, 2010 had reported the adaptation of traditional craft for application on textile base through various techniques namely, heat transfer printing, weaving, embroidery, stencil and block printing respectively. The present study was planned to explore possibility of application of traditional Manipuri designs on contemporary lifestyle product of women i.e., kurti. Kurti was selected from for lifestyle products which are worn as upper garments viz., shirt, kurti, tshirt and waist-coat by the same panel of judges. It may have been selected by the judges due to the fact that kurtiis one of the most common wearable item in the wardrobe of females in the university campus, as a casual or formal dress.

\section{Materials and Methods}

Fifty motifs/designs inspired from Manipuri culture were collected from secondary sources viz., books, articles and other documentations. Twenty-five designs were sourced from textile origin and twenty-five from architectural origin. Ten motifs, five each from textile and architectural origin that represented Manipuri culture effectively were selected from these through order of preferences obtained from a panel of thirty judges from the department of Clothing and Textiles and Family Resource Management, College of Home Science, GBPUAT, Pantnagar. Five line design patterns were prepared for kurtiir respective of the actual designs and one of them was selected. Thereafter, different combinations of motifs were made out of the selected motifs viz., single motif, two motifs, three motifs and four motifs. Five design arrangements were made by placing the motif combinations in the selected line design patterns and one arrangement was selected. Three colour combinations viz., analogous, complementary and split complementary colour on the basis of Pantone 2016 Spring Summer Report, were applied on the selected arrangement and one 
colour scheme was selected for development of heat transfer printing paper. The design arrangement in the selected colour combination was printed onto specially engineered transfer paper with Ultra Chrome DS sublimation ink. Thereafter, raw materials i.e., polyester cotton blend fabric, threads and other accessories were procured from the local market and the lifestyle article was constructed before printing. Designs from transfer paper were printed onto the polyester fabric using the heat transfer printing machine. The printed lifestyle products were assessed for consumers' acceptability usung five point scale on aesthetic parameters viz., combination of motifs in the arrangements, suitability of colour combinations used in design arrangements, uniqueness of designs and design arrangements printing quality and overall appearance.

\section{Results and Discussion}

Total ten motifs were selected, five each from textile source and architectural source. Shamayek, Shamayek, two types of khoiakoibimayek, khamenchatpamayek, and ngamayek were the motifs from textile source whereas human figure with head gear holding enemy's head wearing conch around the neck, deer, upside down tiger, human figure holding each other's shoulders and buffalo head were selected from architectural sources of Manipur.

\section{Description of selected motifs}

\section{Motifs inspired from textile design}

Shamayek: It is a horse motif woven in the border of chirongshangaleirong phi (shawl) with extra weft figuring technique.

Khoiakoibimayek-1: It is acircular arrangement of khoior hook motifs. Akoibi literally means circular in Manipuri. The design is a complex sum of stylized natural, abstract and geometrical motifs where all the component motifs are placed in a specified order signifying specific meaning. It was sourced from embroidered in the border of mayeknaibiphanek (a traditional wraparound worn as lower garment by Manipuri women).

Khoiakoibimayek-2: It is a variation of Khoiakoibimayek. Here, hooks of khoi motif are placed one after the another forming a closed oval shaped pattern with the central space being filled with either simple or compound leaf like motifs.

Khamenchatpamayek: It is derived from the ventral side of serpent god lord Pakhangba.

Ngamayek: It is fish motif is woven along with shamayek in the border of chirongshangaleirong phi (shawl) with extra weft figuring technique.

\section{Motifs inspired from architectural designs}

Human motif-1: It is human figure with head gear holding enemy's head wearing conch around the neck sourced from the carved front wooden wall of the headman's house of Mao tribe of Manipur. Human figure with head gear holding enemy's head wearing conch around the neck represents supremacy over their enemies.

Deer: It is animal design sourced from the wall painting of Talangkai, Kabui house. It is a motif which is adapted from the faunas available in their environment.

Upside down tiger: It is faunal motif sourced from the carved designs in the front walls of Ngaikihouse at Purul village in Senapati district.

Human motif-2: It is human figure holding each other's shoulders represents merry time. 


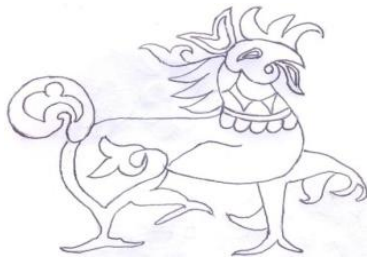

Fig 1 Shamayek (Horse motif)

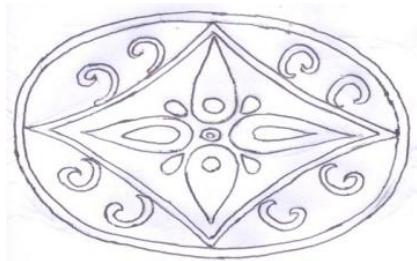

Fig 2 Khoiakoibimayek-1

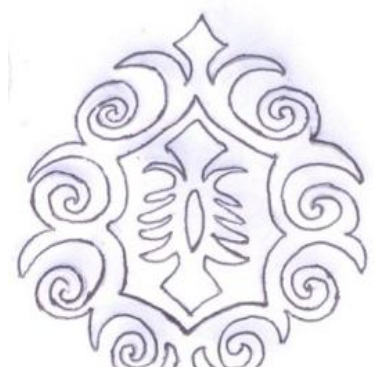

Fig 3Khoiakoibimayek-2

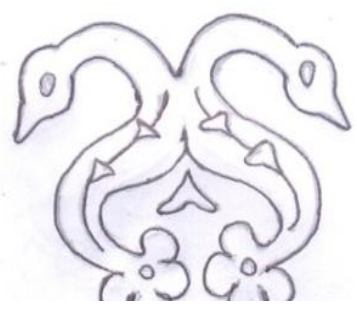

Fig 4Khamenchatpamayek

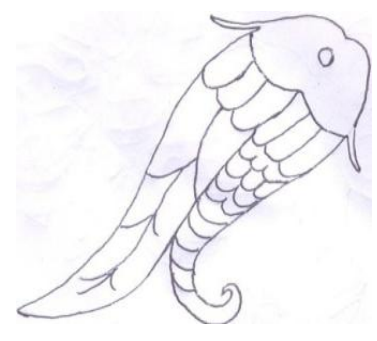

Fig 5Ngamayek

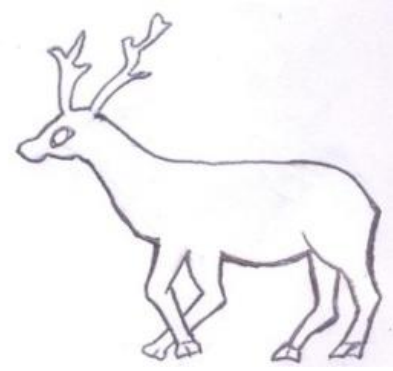

Fig 7 Deer

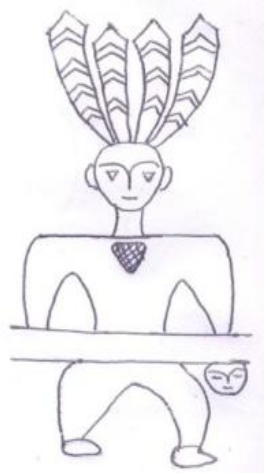

Fig 6 Human motif-1

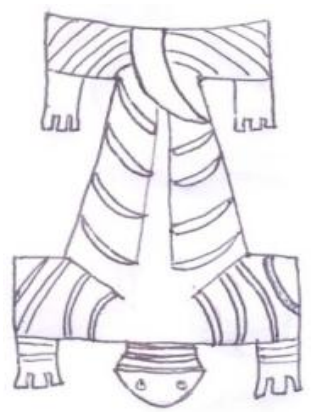

Fig 8Upside down

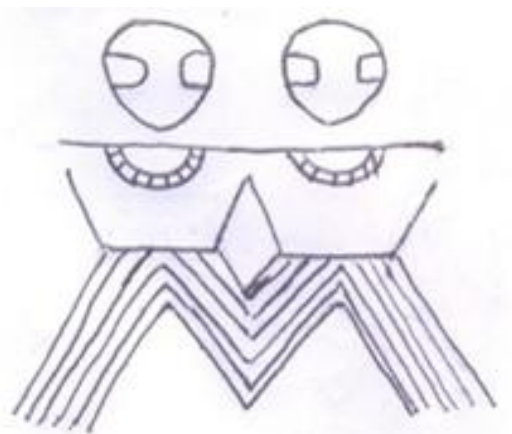

Fig 9Human motif-2

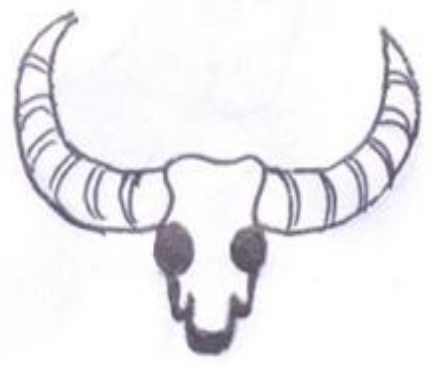

Fig10Buffalo head 
Plate.1 Line design patterns for kurti

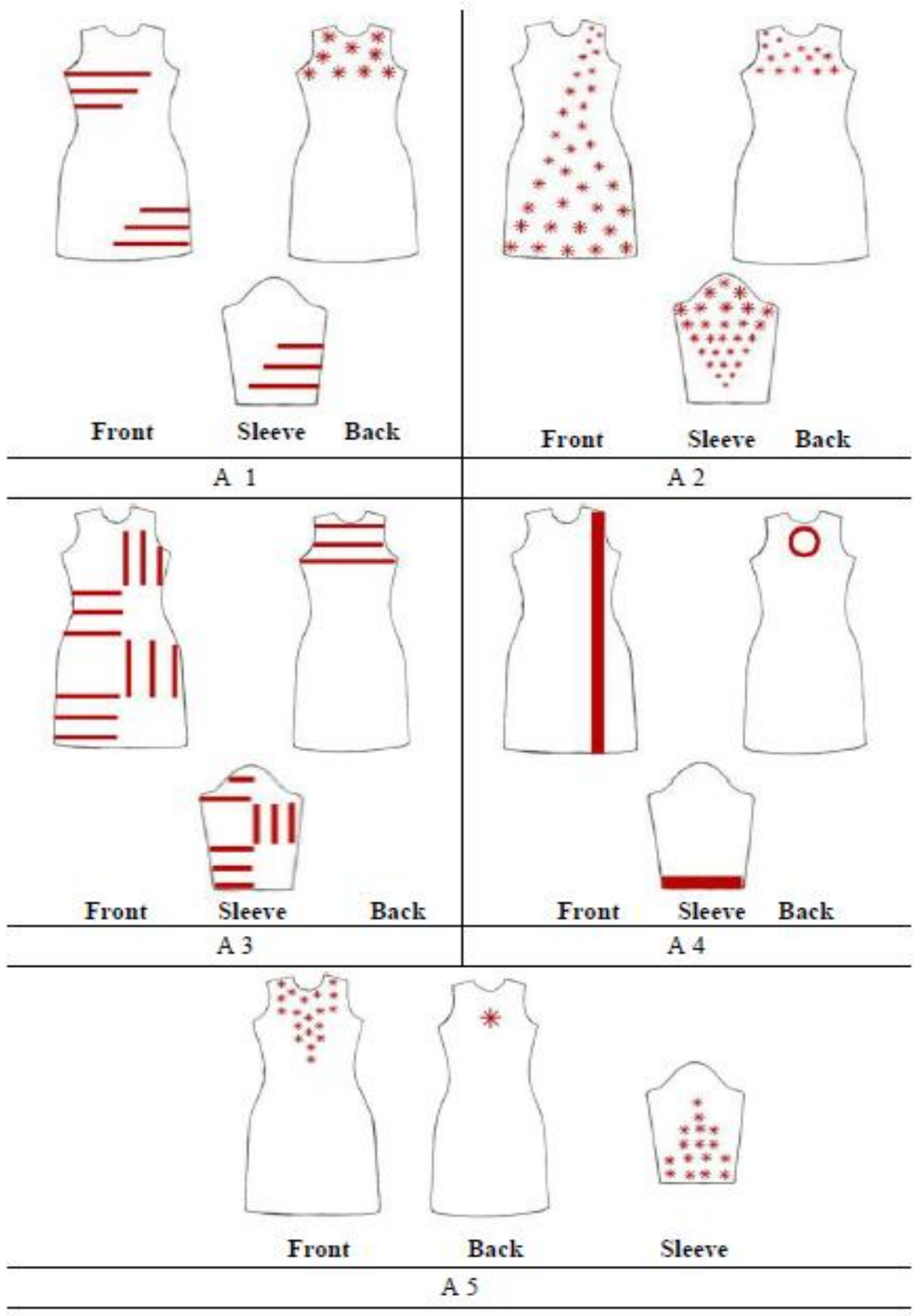


Plate.2 Design arrangements using five design combination for kurti

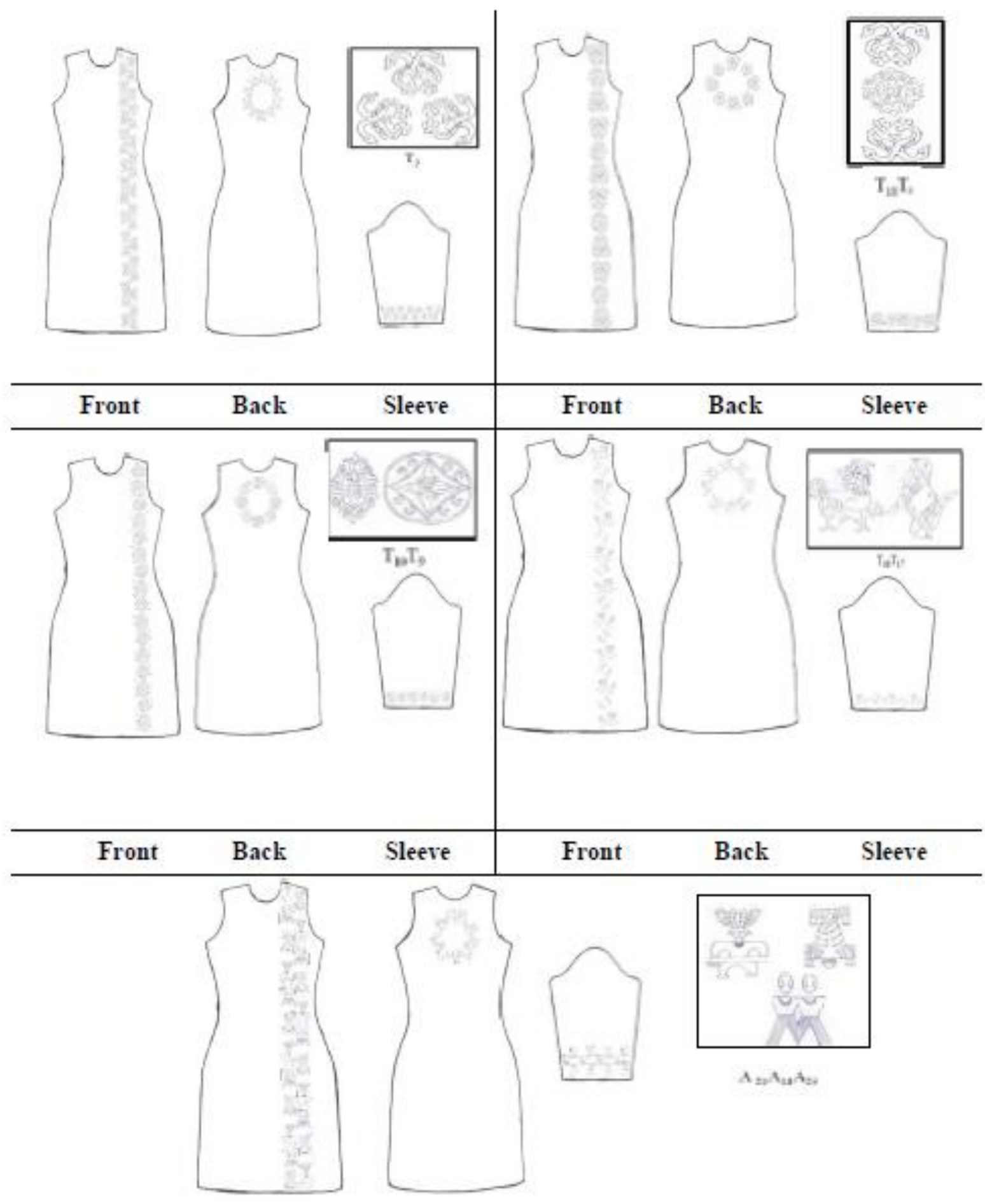

\begin{tabular}{lll}
\hline Front & Back & Sleeve \\
\hline
\end{tabular}


Plate.3 Printed kurti
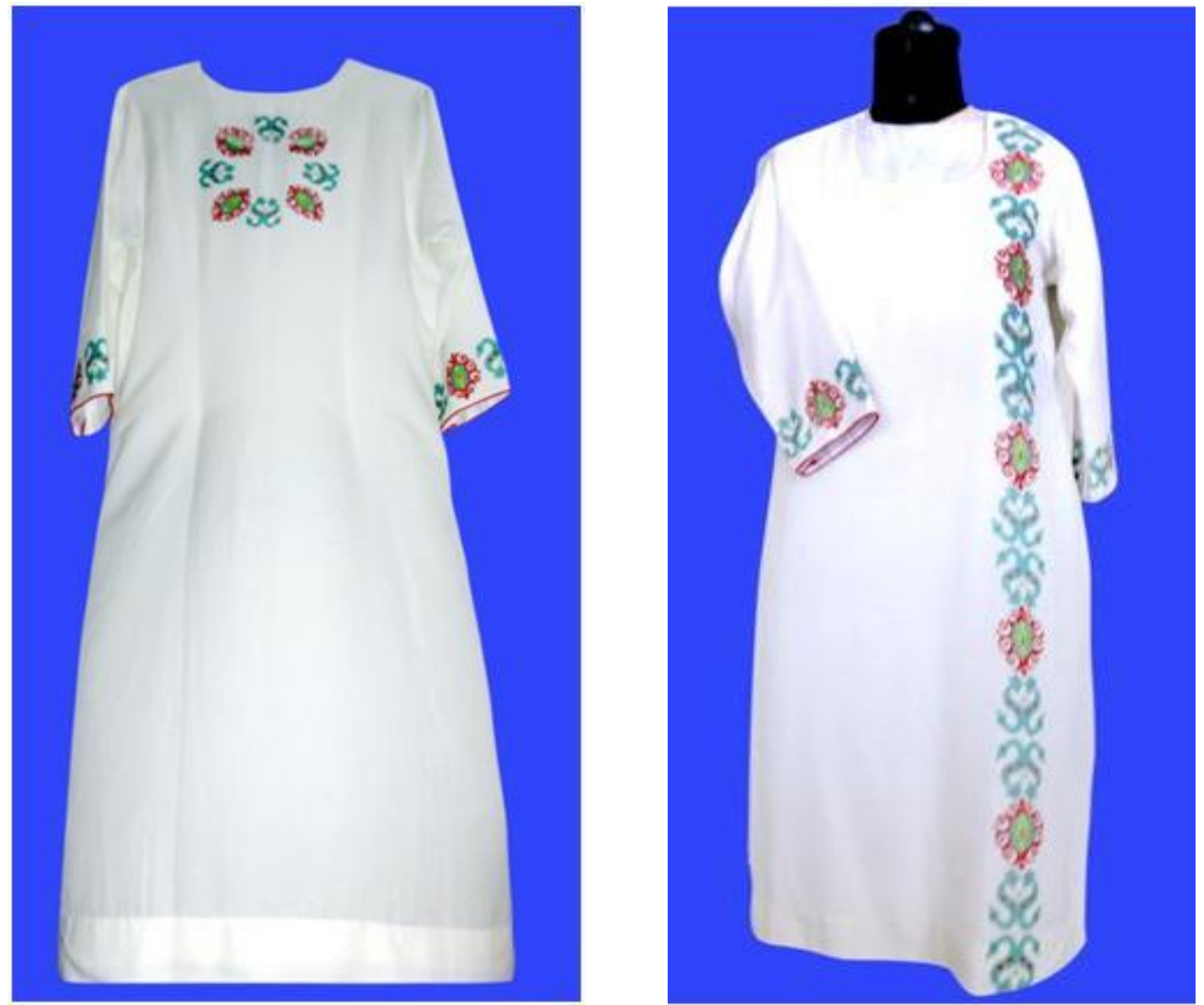

Table.1 Preferences rating for heat transfer printed kurti using adapted Manipuri designs on aesthetic parameters

$\mathrm{n}=30$

\begin{tabular}{|c|c|c|c|c|c|c|c|c|c|}
\hline \multirow{2}{*}{$\begin{array}{l}\text { Sl. } \\
\text { No. }\end{array}$} & \multirow[t]{2}{*}{ Parameters } & \multicolumn{5}{|c|}{ Level of acceptability } & \multirow{2}{*}{$\begin{array}{l}\text { Total } \\
\text { scores }\end{array}$} & \multirow[t]{2}{*}{ WMS } & \multirow[t]{2}{*}{ Ranks } \\
\hline & & Excellent & $\begin{array}{l}\text { Very } \\
\text { good }\end{array}$ & Good & Fair & Poor & & & \\
\hline 1 & $\begin{array}{l}\text { Combination of motifs } \\
\text { in the arrangement }\end{array}$ & $\begin{array}{c}11 \\
(36.66)\end{array}$ & $\begin{array}{c}17 \\
(56.66)\end{array}$ & $\begin{array}{c}2 \\
(6.66)\end{array}$ & - & - & 129 & 4.30 & IV \\
\hline 2 & $\begin{array}{l}\text { Suitability of colour } \\
\text { combination used in } \\
\text { design arrangements }\end{array}$ & $\begin{array}{c}8 \\
(26.66)\end{array}$ & $\begin{array}{c}19 \\
(63.33)\end{array}$ & $\begin{array}{c}3 \\
(10)\end{array}$ & - & - & 125 & 4.17 & V \\
\hline 3 & $\begin{array}{l}\text { Uniqueness of motifs } \\
\text { and design arrangements }\end{array}$ & $\begin{array}{c}20 \\
(66.66)\end{array}$ & $\begin{array}{c}5 \\
(16.66)\end{array}$ & $\begin{array}{c}5 \\
(16.66)\end{array}$ & - & - & 135 & 4.50 & II \\
\hline 4 & *Printing quality & $\begin{array}{c}23 \\
(76.66)\end{array}$ & $\begin{array}{c}5 \\
(16.66)\end{array}$ & $\begin{array}{c}1 \\
(3.33)\end{array}$ & $\begin{array}{c}1 \\
(3.33)\end{array}$ & - & 141 & 4.70 & I \\
\hline 5 & Overall appearance & $\begin{array}{c}15 \\
(50)\end{array}$ & $\begin{array}{c}14 \\
(46.66)\end{array}$ & $\begin{array}{c}1 \\
(3.33)\end{array}$ & - & - & 134 & 4.46 & III \\
\hline
\end{tabular}

*Most preferred parameter** Values in parenthesis indicate percentage 


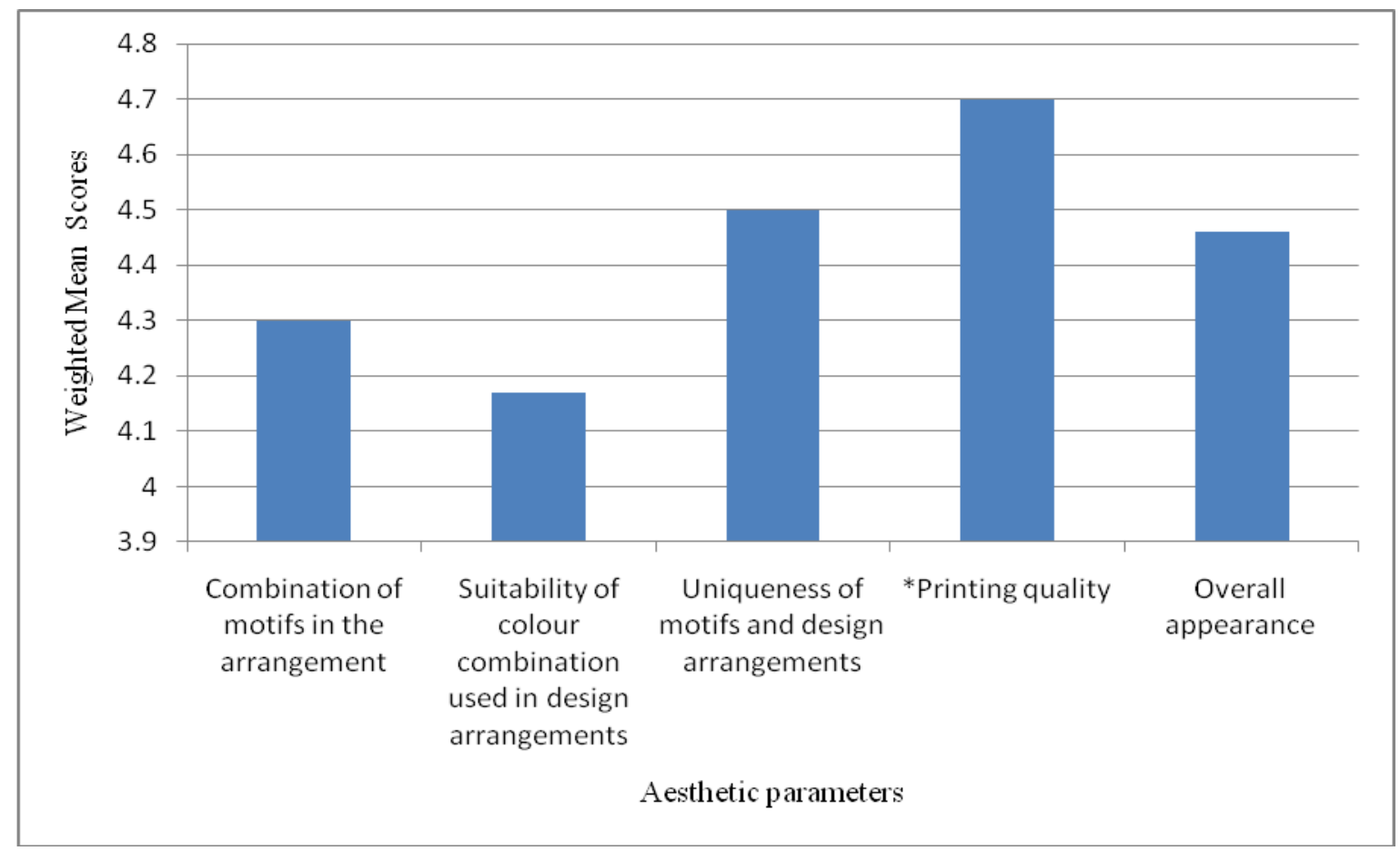

Fig:11Comparisionbetween rating obtained by the aesthetic parameters for the heat transfer printed kurti

Table.2 Cost calculation of kurti

\begin{tabular}{|c|c|c|c|c|}
\hline Sl. No & Parameter & Cost / unit & Amount used & Total cost (Rupees) \\
\hline 1. & Fabric & $40 / \mathrm{m}$ & $4 \mathrm{~m}$ & 180.00 \\
\hline 2. & Transfer paper & $12 \mathrm{p} /$ inch & 93.5 inches & 18.72 \\
\hline 3. & Stitching & & 250 & 250.00 \\
\hline 4. & Printing cost & 4.4/ unit & 0.2083 & 0.9166 \\
\hline \multicolumn{4}{|c|}{ Sub-total } & 449.63 \\
\hline 5. & $10 \%$ overhead cl & of Total 1 & & 44.96 \\
\hline \multicolumn{4}{|c|}{ Grand-total } & 494.59 ( 450 approx) \\
\hline
\end{tabular}

Buffalo head: It is a faunal motif sourced from architecture of Manipur representing the status symbol of a wealthy person in the tribal society. Five line design patterns A 1, A 2, A 3, A 4 and A 5 were prepared in the kurti (Plate 1) irrespective of the actual designs to be placed. Line design pattern scoring highest weighted mean score was assigned rank I and was selected for placement of designs.
The selected line pattern represents vertical placement of a single motif or combination of motifs in the front bodice at the left side, horizontal placement on the sleeve border and circular arrangement at the back. Five design combinations were made by using the ten selected motifs from Manipuri material culture. Thus, five design arrangements were prepared by placing the design combinations 
in the selected line design pattern of the kurti and got assessed. Design arrangement with highest weighted mean score was selected for printing on transfer paper. The selected design arrangement comprises of two designs i.e., khoiakoibimayek -2 and khamenchatpamayek. Finally the printed designs were transferred from paper onto fabric used for making kurti. The printed kurti was assessed by college going female respondents on different aesthetic parameters viz., combination of motifs in the arrangement, suitability of colour combination used in design arrangement, uniqueness of motifs and design arrangement, printing quality and overall appearance on five point rating scale.

It can be drawn from table 1 that majority of the respondents rated the developed kurti as excellent for aesthetic parameters viz., uniqueness of motifs and design arrangements, printing quality and overall appearance followed by very good rating for combination of motifs in the design arrangements, suitability of colour combination used in design arrangements on five point rating scale. Uniqueness of motifs and design arrangement is due to the fact that motifs sourced from Manipuri culture is unique of its kind and its application is not so common as surface designs for contemporary lifestyle products though they have been known for the unique traditional garments. Printing quality is good as the designs are printed on specially engineered paper and at the same time sublimation ink used have good affinity with polyester fabric. The parameter suitability of colour combination used in design arrangement scored the least weighted mean scorebecause consumers might be of the opinion that the colour combination used in the colour ways could have been improved. Table 1 shows that among the five aesthetic parameters, printing quality scored the highest weighted mean score (WMS 4.70) followed by uniqueness of motifs and design arrangement (WMS 4.50), combination of motifs in the arrangement (WMS 4.30), while suitability of colour combination used in design arrangement scored the least weighted mean score (arrangements (WMS 4.17). the weighted means scores of the aesthetic parameters are graphically represented in fig: 11.

\section{Cost of kurti}

The actual cost of the printed kuti was calculated on the basis of the fabric cost, cost of printing designs on paper, stitching charge and, labour cost, electricity charge and 5\% overhead charge born in printing of the lifestyle products. These are simply the cost without profit margins, thus, selling prices of these lifestyle products can be calculated by adding appropriate profit margins to the cost prices of the respective articles. The cost of kurti was Rs 472 (Table 2).

It can be concluded that the research effort resulted in printing of kurti with designs inspired from Manipuri culture through heat transfer printing technique. The respondents highly accepted the printing quality of the motifs and found it unique. It might be due to the fact that the design outlines were clear and sharp. Also, the motifs and designs used were purely regional i.e., Manipur and were still less explored and exposed to the mainstream market compared to the rest of the designs already available in the market. Thus, both at national as well as global levels Manipuri designs have a very promising potential to occupy a place in niche in the fashion market owing to its distinctiveness and newness.

College girls gave positive responses towards the newly developed designs of kuri mainly because of its uniqueness and its soothing colour combination against the background fabric. The present study proves that designs from traditional crafts can be a good source of 
inspiration for designing contemporary lifestyle products. Kurti embellished with designs inspired from traditional textile designs of Manipur is developed through heat transfer printing technique. The process is simple and can be easily carried out in a small room with a printer and a transfer printing machine. Hence, it is physically viable to produce such type of lifestyle product at commercial scale.

\section{References}

Bahadur, M. and Shantabai, Y. 1996. Tribal art of Manipur. $2^{\text {nd }}$ ed. Imphal, Mutua Mueseum. p vii, 1.

Brar, P., Kaur, H. and Sikka, S. 2015. Reinventing the conventional craft of Ikat through screen printed stoles. Textile Trends, 57(2): 39.

Devi, A. I. and Srivastava, M. 2013. Traditional designs of Meitei community of Manipur: adaptation on Salwar-Kameez. Asian Journal of Home Science. 8(1): 264-268.

Jangwan, M. 2009. Rejuvenate the Kalamkari with heat transfer printing on kurtis. Thesis. M.Sc., Banasthali Vidyapith. p 67.
Joshi Y. 2004. Adaptation of Kumaoni folk designs for Block Printing. Thesis. M.Sc. GBPUAT, Pantnagar.

Kapur, H. and Mittar S. 2014. Design intervention \& craft revival. International Journal of Scientific and Research Publications, 4(10): 1-4.

Karolia, A. and Buch, H. 2008. Ajrakh- The resist printed fabric of Gujarat. Indian Journal of Traditional Knowledge. 7(1): 93-97.

Karolia, A. and Prakash, R. 2014. Design and development of fashion accessories inspired from the hand woven shawls of Nagaland. Asian Journal of Home Science. 13(2): 416.

Kaur, M., Bains, S. and et al., 2014. Traditional and modern expression of Phulkari. Asian Journal of Home Science. 9(2): 460.

Keisham S., 1998. Traditional dress of the Meiteis. Imphal, Bhubon Publishing House. 6-10p.

Pandya, A. and Vishwakarma, A. 2010. Rogan- the traditional hand painted textile of Gujarat. Indian Journal of Traditional Knowledge, 9(4):644-650.

Pandya, J. and Thoudam, J. 2010. Handloom weaving, the traditional craft of Manipur. Indian Journal of Traditional Knowledge, 9(4): 651.

\section{How to cite this article:}

Laimayum Jogeeta Devi, Anita Rani and Manisha Gahlot. 2019. Designing of Kurti Using Traditional Designs of Manipur through Transfer Printing. Int.J.Curr.Microbiol.App.Sci. 8(08): 267-276. doi: https://doi.org/10.20546/ijcmas.2019.808.032 